Curr Treat Options Neurol. 2016 September ; 18(9): 40. doi:10.1007/s11940-016-0424-3.

\title{
Treatment of sleep disorders in dementia
}

\author{
Sharon Ooms, $\mathbf{M S c}^{\mathrm{a}, \mathrm{b}}$ and $\mathrm{Yo}-\mathrm{EI} \mathrm{Ju}, \mathrm{MD}, \mathrm{MSCI}^{\mathrm{C}}$ \\ aDepartment of Geriatric Medicine, Radboud University Medical Centre, Nijmegen, the

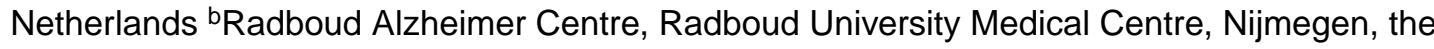 \\ Netherlands 'Department of Neurology, Washington University School of Medicine, St Louis, \\ Missouri
}

\section{Keywords}

sleep; insomnia; circadian; dementia; Alzheimer's disease; dementia with Lewy bodies; Lewy Body disease; vascular dementia; frontotemporal dementia; Parkinson's disease with dementia; REM sleep behavior disorder

\section{Introduction}

Dementia is associated with sleep and circadian disturbances, worse than the expected gradual sleep quality with aging[1], which negatively affect patient quality of life and increase caregiver burden [2]. Disrupted sleep and circadian functions in dementia are attributed to neurodegeneration of brain regions and networks involved in these functions, such as the suprachiasmatic nucleus [3, 4]; however, there are additional factors that contribute to the burden of sleep disturbances in dementia. Alzheimer's Disease (AD) is associated with a delay in circadian phase, unlike the typical advance in circadian phase with aging [5]. This delay likely contributes to sundowning-agitation and confusion in the evening — as well as to difficulty sleeping at night. Due to wandering and subsequent risk of injury, nighttime insomnia increases morbidity and mortality directly, and therefore is a common reason for institutionalization [6]. During the daytime, excessive sleepiness may contribute to worse cognitive function, unintentional naps that impact driving safety, and decreased ability to engage in social functions and therapies. Given the substantial negative impact of sleep and circadian problems in dementia patients, there is keen interest in identifying effective treatments, with the hope of reducing caregiver burden, improving patient quality of life, postponing institutionalization, and potentially slowing cognitive decline.

\section{Dementia subtypes and sleep disorders}

Various etiologies of dementia are associated with different types of sleep and circadian disturbances. In $\mathrm{AD}$, the most common cause of dementia, $44 \%$ of patients are affected with

Corresponding author: Yo-El S. Ju, MD, MSCI, Washington University School of Medicine, 660 South Euclid Avenue, Box 8111, Saint Louis, MO 63110, Phone: 314-747-3824, Fax: 314-747-3813, juy@ neuro.wustl.edu. 
a sleep disorder[7, 8], and the prevalence and severity of sleep disorders increase with dementia severity. Sleep disturbance occurs very early in AD; even the preclinical stage of $\mathrm{AD}$ prior to cognitive symptoms is associated with worse sleep quality and shorter sleep duration $[9,10]$. There is increasing evidence that there is a bi-directional relationship between AD pathology, especially amyloid- $\beta$ plaque accumulation, and poor sleep[11]. Additional sleep disturbances in $\mathrm{AD}$ include daytime hypersomnia, delayed circadian phase, sundowning, and adverse effects of dementia medications such as acetylcholinesterase inhibitors [12]. Obstructive sleep apnea (OSA), a primary sleep disorder, is particularly common in $\mathrm{AD}[13,14]$.

Dementia with Lewy bodies (DLB) and Parkinson's disease (PD) with dementia (PDD) are pathologically similar and can be grouped together as Lewy Body Disease (LBD). LBD has the highest prevalence of sleep and circadian disturbances of any dementia, affecting approximately $90 \%$ of patients [15]. Insomnia is the most common sleep disturbance in LBD, a combination of prolonged sleep latency, increased sleep fragmentation, nightmares, and early-morning awakenings [16]. Daytime hypersomnia, including "sleep attacks," is also common ( $\sim 50 \%$ prevalence) and contributes to worse quality of life and safety risks in LBD[17, 18]. Hypersomnia may be related to loss of orexinergic neurons[19] However, there are no studies correlating orexin (hypocretin) levels with hypersomnia severity in LBD. Hallucinations, particularly visual hallucinations in the evening or night, may contribute to sleep problems in LBD. In terms of primary sleep disorders, REM sleep behavior disorder (RBD), a parasomnia characterized by potentially violent or injurious dream enactment behavior, is common in LBD and is a supportive diagnostic criterion for DLB. In fact, the majority of patients with RBD in "idiopathic" form without dementia develop LBD eventually[20]. Another primary sleep disorder associated with PD is restless legs syndrome (RLS), with a prevalence of approximately $20 \%$ [21].

Vascular dementia (VD), the second leading cause of dementia, is commonly associated with OSA. In the acute post-stroke period, there is a high prevalence of central apneas, which typically resolve[22]. Otherwise, due to the wide range of vascular disease (localization in the brain, micro- versus macro-vascular disease, and co-occurrence with other neurodegenerative pathology), there are no other characteristic associations with specific sleep disorders or symptoms.

There is a similar prevalence of sleep disorders in frontotemporal dementia (FTD) as in AD, but they differ in their manifestation[23]. The activity rhythm in FTD is more fragmented, and there can be circadian advance or delay[24].

In addition to the sleep and circadian disturbances primarily associated with various dementias, there are additional factors that may worsen symptoms or complicate treatment. Co-morbidities that cause pain or discomfort, or psychiatric conditions such as depression[15], worsen nighttime insomnia. Medications for the underlying dementia as well as medications for co-morbid conditions (e.g. $\beta 2$ agonist inhalers for pulmonary disease, anti-hypertensive medications) may contribute to sleep disturbance. Sleep hygiene, which includes the regularity and timing of sleep, napping, bedtime ritual, daytime activity, light and nocturnal noise (especially in nursing homes [25]), may be poor in dementia and 
therefore exacerbate sleep-wake problems[8]. Due to the complex inter-relationships between dementia pathophysiology, dementia effect on sleep hygiene, co-morbid primary sleep disorders, medication effects, and other factors, a comprehensive approach is necessary for diagnosis and treatment of sleep disorders in dementia. (Table 1)

\section{Assessment}

Assessment of sleep and circadian disturbances in dementia begins with a complete history. Since demented people may not recall symptoms accurately, collateral history from caregivers is essential. The clinical history should assess for symptoms of primary sleep disorders, such as snoring, hypersomnia, witnessed apneas, parasomnias, restless legs, and leg movements during sleep. The timing and regularity of nighttime sleep and daytime naps (intentional and inadvertent) are important to ascertain. In addition to these clinical features typically queried during a sleep evaluation, individuals with dementia should be specifically asked about sundowning, hallucinations, sleep attacks, injurious parasomnias, and nighttime wandering. If the cause of dementia is known, the history should query for sleep-wake problems characteristic of the underlying disease. For example, in someone with Parkinson's Disease, a detailed temporal relationship between dopaminergic medication dosing and RLS symptoms should be obtained. In all cases, the overall burden of sleep disturbances on both patient and caregiver should be taken into account.

Contributory factors should be assessed, including 1) depression and anxiety; 2) comorbidities causing pain or discomfort; 3 ) co-morbidities that cause awakenings (e.g. prostatic hypertrophy causing frequent nocturia); 4) medications including supplements and over-the-counter medications; 5) current and prior alcohol, tobacco, caffeine, and other substance use; 6) living and sleeping arrangements; 7) degree, frequency, and regularity of physical activity; 8) social and occupational activity; 9) timing and regularity of meals; 10) light and noise exposure during daytime and nighttime.

Scales typically used for sleep evaluation, such as the Epworth Sleepiness Scale (ESS) [26] or Pittsburgh Sleep Quality Index (PSQI) [27] have not been validated specifically for use in dementia, and, caregivers may complete questionnaires for patients. Therefore, typical normal/abnormal cutoffs may not be applicable. However, these and other scales are still useful for following individual trends over time. Additionally, dementia-specific scales may be helpful. Examples include the Sleep Disturbance Inventory (SDI), which was developed to assess caregiver burden due to sleep disturbance in $\mathrm{AD}$ [28], and the Behavior Pathology In Alzheimer's Disease Rating Scale (BEHAVE-AD). In LBD, the Parkinson's Disease Sleep Scale and the SCOPA-sleep scale may be helpful[29].

Objective data about circadian activity patterns and overnight sleep are helpful for diagnosing sleep disorders and assessing response to treatment. Sleep logs alone may not be accurate in individuals with dementia. Actigraphy, using non-invasive wearable motion sensors, is helpful for assessing suspected circadian disorders. Furthermore, validated sleepscoring algorithms are available to analyze actigraphy data, to calculate objective measurements of nocturnal sleep such as total sleep time and sleep efficiency. The standard practice committee of the American Academy of Sleep Medicine (AASM) has 
recommended actigraphy and sleep logs to be routinely used to assess for irregular sleep wake rhythms in dementia[30].

If there are symptoms of a primary sleep disorder such as OSA, periodic limb movement disorder, or RBD, polysomnography (PSG) is the gold standard for diagnosis. If possible, a caregiver should stay in the sleep lab to assist with PSG, since a strange environment and numerous sensors may cause confusion. Ambulatory studies for OSA can be done in the patient's usual sleeping environment, however patients with dementia may have difficulty using the home recording devices. Additionally, ambulatory studies are less sensitive for mild OSA compared to PSG[31].

\section{Approach to treatment}

The treatment approach to sleep problems in dementia is similar to that in the general population, but with additional attention paid to avoid exacerbating cognitive dysfunction, reducing injury risk, and reducing caregiver burden. First, any underlying primary sleep disorders should be assessed for and treated. Second, any co-morbid mood and anxiety disorders should be addressed. Third, pain, nocturia, or other comorbid conditions that interfere with sleep should be addressed to the best extent possible, and medications that affect sleep (including those for the underlying dementing disease) should be adjusted to optimize sleep-wake functioning. For example, acetylcholinesterase inhibitors (e.g. donepezil and rivastigmine) and MAO-B inhibitors (e.g. selegiline) may cause insomnia, and dosing should be moved earlier in the daytime. Additionally, dopaminergic medications for Parkinsonism should be adjusted to minimize bothersome nighttime motor symptoms that may awaken the patient, as well as minimize sedating effects during the daytime (especially dopamine agonists). Management of a patient's co-morbid conditions and medications requires close co-ordination with the patient, the caregiver, and the patient's other physicians and other healthcare professionals, and is usually the most time-consuming aspect of care of demented patients with sleep disturbances. Lastly, if sleep-wake problems persist, nonpharmacological treatments are preferred, due to the risk of sedation, cognitive symptoms, falls, injuries, and medication interactions with pharmacological treatments. In recalcitrant cases, pharmacological treatments can also be added cautiously. Ideally, objective measurements such as actigraphy and subjective measurements of patient and caregiver symptoms should be obtained serially to follow response to treatment.

\section{Treatment of primary sleep disorders}

The treatment of sleep disturbance in dementia should always begin with treatment of any primary sleep disorders. Sleep disorders increase with aging, and are very common in people with dementia. In the general population, OSA contributes to nighttime sleep fragmentation, insomnia, daytime hypersomnia, cognitive dysfunction, and decreased mood. Therefore, it is expected that in the demented population, OSA would have similar and potentially worse effects. OSA is very common in $\mathrm{AD}$, present in $40 \%$ of $\mathrm{AD}$ patients overall and increasing to $70 \%$ in the institutionalized setting $[13,14]$. In fact, having OSA increases risk of dementia. In the Study of Osteoporotic Fractures, OSA increased the risk of incident cognitive decline by an adjusted odds ratio of 1.85[32]. In the AD Neuroimaging Initiative 
cohort, participants who reported having OSA were diagnosed with mild cognitive impairment and $\mathrm{AD}$ about 13 and 5 years earlier, respectively, than those who did not. [33]. In patients who already have dementia, the existing data support treating any OSA. In a small, randomized study of demented patients, treatment of OSA with positive airway pressure (PAP) helped slow cognitive decline[34]. Furthermore, in a longitudinal extension of the study, PAP was associated with improved subjective sleep scores such as ESS and PSQI[35]. In another nonrandomized study of 23 mild to moderate AD patients with severe OSA, there was a slower decline in cognition if patients used PAP; the effect as measured by Mini-Mental Status Exam score was a decline of 0.7 points annually for PAP versus 2.2 points annually without PAP [36]. OSA is also common in vascular dementia, however no randomized studies of PAP have been published about this population. Non-PAP treatments such as mandibular advancement devices have not been tested in randomized studies in the dementia population, but may be a reasonable alternative in patients who are unable to use PAP.

Restless legs syndrome and periodic limb movement disorder (PLMD) are common in LBD, especially PDD. Treatment approach is the same as idiopathic RLS and PLMD. Iron deficiency can worsen RLS and PLMD, and should be treated with supplementation. Medications typically used for RLS and PLMD such as dopamine agonists and gabapentin are effective in the demented population, however, since dopamine agonists are also prescribed for motor symptoms, treatment regimens should be coordinated between sleep medicine and dementia/movement disorders physicians.

REM sleep behavior disorder requires PSG confirmation, showing REM sleep without atonia[37]. Behavioral precautions including removing weapons from the bedroom, moving furniture far from the bed, and putting a rug on hard floors should be advised. In cases where the patient or bed-partner are at risk of injury, both clonazepam and melatonin have been shown to be effective for reducing oneiric behaviors [38]. Melatonin is preferred if there is concern for cognitive or sedating side effects of clonazepam. In all patients with PD, RBD should be assessed for because it is prognostically useful; RBD predicts a PDD phenotype and more rapid progression[39]. Unfortunately, treatment of RBD symptoms has not been shown to slow the progression of the underlying neurodegenerative process.

Hypersomnia may persist despite treatment of primary nocturnal sleep disorders, particularly in LBD. Some dementia patients meet formal criteria for narcolepsy or idiopathic hypersomnia. Treatment with stimulant medications, anti-cataplectic agents, or sodium oxybate may be appropriate if patients have bona fide narcolepsy, however, exceptional care should be taken to minimize side effects, particularly worsening of cognitive symptoms or any co-morbid cardiovascular disease.

\section{Non-pharmacological treatments}

\section{Sleep hygiene education}

Optimal sleep hygiene includes behaviors that promote consolidated sleep at night, including regular and adequate nocturnal sleep periods, minimizing naps, minimizing sleep-disrupting substances (alcohol, tobacco, caffeine, and other), obtaining regular vigorous physical 
activity, avoiding excessive light close to bedtime, developing a bedtime routine to transition from wake to sleep, sleeping in a sleep-conducive (dark, cool, quiet, no television) environment, and using the bed only for sleep (i.e. stimulus control). Educating dementia patients and their caregivers about sleep hygiene has generally been used as a control group for other interventions, or has been used in combinations with other approaches in multimodality treatment[40-42]. In one small study of dementia patients residing in group homes, sleep hygiene education resulted in a longer total sleep time at night as measured by actigraphy, 9.6 hours, as compared to controls, 7.8 hours[43]. Sleep efficiency, the percentage of time in bed that is spent asleep, also was improved, $84 \%$ in the sleep hygiene group versus $75 \%$ in controls[43]. However, another study in more severe, institutionalized dementia patients, did not find any positive effect of sleep hygiene education [44]. In general, although strong data for sleep hygiene education in dementia are lacking, since there are no anticipated adverse effects, good sleep hygiene serves as a foundation for insomnia treatment, including in the dementia population.

\section{Physical and social activity}

Increased daytime physical activity and social interaction have been shown to improve daytime alertness and nighttime sleep in the elderly population[45-48]. Potential mechanisms include increase of slow wave sleep following physical exertion, stronger circadian zeitgebers from regular physical/social activity, psychological factors, or other mechanisms. Many studies of physical and social activity as sleep interventions have used multi-modality treatment, therefore individual benefits of physical or social activity are difficult to ascertain. In an early study, a combination of sleep hygiene education, daily walking for 30 minutes, and bright light therapy for 1 hour at night decreased wake time at night by 36 minutes after 2 months of treatment[42]. A study of only exercise, 30 minutes of walking for 5 days per week, in moderately demented nursing home patients, showed no benefit on sleep [49]. McCurry et al compared physical activity (daily walking for 30 minutes for 2 months), bright light therapy, a combination of both, and control (sleep hygiene instruction) groups. They found that there was decreased wake time overnight on actigraphic measurement initially, but there were no significant benefits at 6 months [50]. A randomized controlled study in $\mathrm{AD}$ and $\mathrm{PD}$ showed a positive effect of more intense, structured physical activity. In this study, patients had exercise sessions for 1 hour, 3 times per week, for 6 months. Exercise routines were designed, individualized, and supervised by professionals, to target $60-80 \%$ of maximal heart rate. Participants who were able to maintain this level of regular physical activity demonstrated benefit in sleep as measured by the Mini Sleep Questionnaire, and in daily activities [51].

Social and occupational activities provide zeitgebers for circadian clock entrainment and discourage people from sleeping during the daytime. In a demented, nursing-home population, an intervention of only structured social activity reduced actigraphicallymeasured daytime sleep, and - in the subset of participants with poor nighttime sleep efficiency-increased nighttime total sleep time [48]. In a larger study that examined general nursing home and assisted-living center residents, a combination of structured social activity and physical activity improved nocturnal sleep as measured by PSG, however, neither intervention alone had a significant effect [47]. 
Overall, structured physical and social activities have neutral to positive effects on sleep, with a trend for more benefit with multi-modality treatment and with more vigorous physical activity. Again, in the interest of minimizing harm, this type of intervention should be encouraged as tolerated in demented patients with sleep and circadian disturbances, prior to pharmacological therapies. Unfortunately, there are no widespread, standardized programs for structured physical or social activity in dementia, although training programs for caregivers are under development[52]. Therefore, in clinical practice, patients should be advised to exercise vigorously regularly (3-5 times per week for 30-60 minutes), if possible with a professional trainer using a target heart rate. Additionally, all demented patients should be advised to have regular social interactions, although there are no formal or standard recommendations for frequency, quantity, or quality.

\section{Bright light therapy}

Bright light therapy (BLT) is an intervention used to treat circadian disorders. BLT involves exposure to light, which activates the retinohypothalamic tract to the suprachiasmatic nucleus, thereby entraining circadian phase. The effect of light on circadian phase depends acutely on the time the light is delivered: light close to bedtime delays phase, while light close to waketime advances phase. The AASM has published parameters for the use of BLT in circadian disorders[53]. Studies investigating the effect of BLT specifically in dementia patients show mixed results. A systematic Cochrane meta-analysis in 2014 examined the effectiveness of BLT on sleep disturbance in dementia [54], and included 10 studies assessing sleep [50, 55-63]. Seven of the studies delivered BLT using a light box (2500-10,000 lux) for 1-2 hours [50, 55-60], while other methods were used for the other studies [61-63]. BLT was administered in the morning[57-60, 63], evening[50], both [55, $56]$, or all day [61, 62]. Treatment duration ranged from 10 days to 10 weeks. Sleep was measured in all studies with total sleep time, except for one that assessed nighttime activity[60]. Pooled data revealed no effect of BLT on nocturnal total sleep time. However, there was a significant decrease in night-time awakenings, particularly in the studies using morning BLT. There were insufficient data to clearly recommend any of the BLT modalities, dose (lux or duration), timing, or treatment duration options tested. Two additional small, randomized studies have been published since that review, again with neutral to positive effect of BLT[64, 65]. Another meta-analysis, by van Maanen et al in 2015[66], included 5 studies excluded from the Cochrane review (for not being randomized controlled trials) [67-71], and excluded 5 studies included in the Cochrane review (because inclusion criteria required a sleep complaints) $[55,56,59,61,63]$. This meta-analysis reported a significant benefit of BLT for sleep disturbances in dementia, for sleep onset latency, total sleep time, time in bed, and sleep efficiency. To summarize, data regarding BLT for sleep disturbances in dementia are mixed but generally trend toward a positive effect, with the most potential benefit for morning BLT and for individuals with sleep disturbances. Since BLT does not have significant adverse effects, it is reasonable to try morning BLT (particularly in combination with melatonin as discussed below), in demented individuals who have a sleep disturbance or delayed circadian phase. 


\section{Complementary alternative medicine}

Several complementary and alternative modalities have been tested for sleep disturbances in dementia. Two small, non-randomized studies reported an improvement of sleep in dementia after acupuncture or accupressure [72,73]. A randomized trial of a 3-minute back massage prior to bedtime showed a 36-minute, but non-significant, improvement in total sleep time [74]. A small, randomized study of Tai Chi in vascular dementia demonstrated a benefit in sleep, as measured by PSQI [75]. A study of a child-like robot for elderly women living alone (not necessarily with dementia) showed significant improvement in several sleep variables, including total sleep time, compared to a more mechanical robot[76]. These and other alternative, non-pharmacological interventions are under active investigation for sleep disturbance in dementia, however, none have been demonstrated to be effective in rigorous, double-blind, randomized, controlled trials. In general, if a patient or caregiver wants to pursue a potential non-pharmacological intervention without anticipated adverse side effects or excessive cost, it is reasonable to perform a trial of the intervention, with serial objective measurements (such as actigraphy) or subjective scales over a short period, to assess response.

\section{Pharmacological treatment}

\section{Melatonin}

Melatonin is released from the pineal gland in the evening in dim light, and mediates the relationship between the circadian clock and sleep. Exogenous melatonin has circadian phase-shifting effects opposite to that of light, and also exerts a mild soporific effect. Melatonin levels are decreased in $\mathrm{AD}[77,78]$. Melatonin has been shown to improve cognition, emotional performance, and sleep-wake patterns in mild cognitive impairment[79], suggesting a possible beneficial role for melatonin in dementia. However, existing data on melatonin in dementia are equivocal. A Cochrane meta-analysis in 2014, including 3 randomized, controlled studies [58,80,81], found no benefit of melatonin in dementia patients with sleep complaints[82]. Dowling et al used melatonin $5 \mathrm{mg}$ for 10 weeks, in a mixed-modality treatment with BLT, and found a benefit[58]. Serfaty et al used 6 $\mathrm{mg}$ slow release melatonin for two weeks[80], and Singer et al used 10 or $2.5 \mathrm{mg}$ for 8 weeks[81]; neither study found any difference between melatonin and control groups. Another meta-analysis in 2015 by Xu et al included 7 randomized, controlled studies that examined melatonin in people with dementia, not necessarily with sleep problems[83]. This meta-analysis included four studies in addition to the three in the Cochrane review[61, 84-86], and found a benefit for melatonin of approximately 24 minutes on TST, small ( 2\%) improvements in sleep efficiency, and no cognitive benefits. The largest study included 189 nursing home residents, the majority $(87 \%)$ of whom had dementia. In this study, melatonin $2.5 \mathrm{mg}$ given 1 hour before bedtime increased sleep duration by 27 minutes. However, melatonin was associated with worse withdrawn behavior and depression; the behavioral effects were ameliorated by BLT [61]. Of the other three studies, one showed no effect of either $8.5 \mathrm{mg}$ immediate release or $1.5 \mathrm{mg}$ sustained release melatonin at 10PM, [85] one showed a small improvement with $3 \mathrm{mg}$ melatonin at 10:30 PM in total sleep time [84], and one did not assess sleep outcomes[86]. Another more recent randomized controlled study using $2 \mathrm{mg}$ slow release melatonin for 24 weeks in a multi-site study of mild-to-moderate 
$\mathrm{AD}(\mathrm{n}=80)$ [87], found that, compared to placebo, there was less decline in mini mental state examination (MMSE) and instrumental activities of daily living (IADLS) with melatonin. Sleep was assessed only with PSQI, and only the sleep efficiency component of this index improved; this difference was more pronounced for those starting with insomnia as defined by PSQI $\prec 6,(n=13)[87]$.

Melatonin receptor agonists such as ramelteon simulate the action of melatonin. One randomized controlled trial has been performed with ramelteon. There is no publication associated with this study, however the synopsis of the study from the manufacturer[88] and a summary of information provided to the Cochrane meta-analysis investigators[82] were reviewed. There was no benefit of ramelteon after 1 week on actigraphically-determined total sleep time in mild to moderate AD patients. No data are available regarding outcomes at the end of the planned 8-week treatment period. Ramelteon was also assessed in a small case study in four PDD patients, in which scores of ESS and PSQI improved in all patients after treatment with ramelteon for 8 weeks[89]. There are several reports of a beneficial effect of ramelteon on sundowning or delirium; these studies are beyond the scope of this review.

Altogether, the existing data on melatonin suggest a possible benefit in terms of nocturnal sleep of approximately half an hour, and reduced frequency of awakenings. There is no known benefit of ramelteon or extended-release melatonin. Melatonin is considered a nutritional supplement in the US and is not subject to the same standards as a prescription medication. Furthermore, different dosages and timing (which affects phase shifting action of melatonin) varied between studies. Therefore, it is difficult to suggest a specific dose or timing, particularly since many of the studies used dosing at bedtime, which is later than would be typically used to advance sleep phase. Additionally, there was possible negative effect on mood and behavioral indices in one study, except when combined with BLT. In general, melatonin is well-tolerated with minimal side effects at low doses. Therefore, in individuals who do not respond to maximal behavioral interventions, it is reasonable to try a low dose of melatonin (2-5 mg) at night, together with BLT, while closely monitoring for depressive symptoms, and objectively following sleep/circadian measurements.

\section{Sedating anti-depressants}

Sedating anti-depressants are prescribed frequently for their soporific qualities, but there are very limited data on anti-depressants for sleep in dementia. One study of trazodone $50 \mathrm{mg}$ at bedtime in $\mathrm{AD}$ demonstrated an improvement of 42.5 minutes in total sleep time at night, and there were no significant adverse effects—including cognitive- that were reported[90]. Another study, of mirtazapine $15 \mathrm{mg}$, found no benefit on sleep after 2 weeks in AD patients, and there was increased daytime sleepiness [91]. Interestingly, a meta-analysis of cost-effectiveness of depression treatment in dementia found no cost benefit to either mirtazapine or sertraline compared to no treatment, however the number of caregiver hours required was reduced with mirtazapine, 6.7 versus 12.3 hours, which the investigators hypothesized was due to improved sleep in the mirtazapine group[92]. Anti-depressants with anti-cholinergic properties (such as tricyclic antidepressants) may worsen cognition in $\mathrm{AD}$ and LBD, and most anti-depressants also worsen RLS. Therefore, while modest data suggest 
trazodone may improve nocturnal sleep in dementia, sedating anti-depressants should be used cautiously, with close monitoring of cognitive and RLS symptoms.

\section{Benzodiazepine receptor agonists}

Typical benzodiazepines, especially long acting ones, have been associated with increased risk of falls, anterograde amnesia, daytime sleepiness, confusion, negative effect on cognition, and risk of dependence or abuse[3, 93]. Long term usage of benzodiazepines has been suggested to be associated with an increased risk of $\mathrm{AD}$ [94-96], but this association is not conclusive [97]. Non-benzodiazepine benzodiazepine-receptor agonists (NBBRAs, e.g. zolpidem and zaleplon) are preferred, since they have a shorter half-life and are generally better-tolerated, with less risk of dependence or abuse. However, NBBRAs have not been tested specifically in the dementia population. Furthermore, they are associated with adverse side effects such as morning sedation and parasomnias in the general population, and falls in the older population $[3,98]$. Therefore these medications should be used sparingly only in demented patients who have attentive caregivers and living/sleeping situations that maximize safety, and patients should be seen frequently to assess for potential side effects and to ensure objective improvement in sleep.

\section{Other hypnotic medications}

In a small (20 treatment vs 22 placebo) post-hoc analysis of a memantine trial in LBD, there was less nocturnal activity in the memantine group measured by questionnaire, but no differences in ESS. The decrease in nocturnal activity was interpreted as reduced RBD, however this finding has not been confirmed by PSG[99].

In a non-randomized study of newly-diagnosed AD patients, those with frequent awakenings per night $(\mathrm{n}=93$ ) were offered treatment with risperidone $0.5-1 \mathrm{mg}$, zolpidem 5-10 mg, melatonin $2.55 \mathrm{mg}$, or no drug treatment, in addition to donepezil 5-10mg. After 5 years, the risperidone group did not have deterioration in ESS and PSQI, compared to the other groups, who had worsening in both measures [100].

There are no reports of trials of orexin recenptor antagonists (e.g. suvorexant) or other hypnotic classes in dementia.

\section{Stimulants}

While stimulants such as methylphenidate have been tested in dementia to address apathy, there are limited studies examining stimulants for hypersomnia in dementia. Daytime hypersomnia is particularly common in LBD, and two small studies examined modafinil for this indication. One showed slight improvements in physical fatigueability but not hypersomnia [101], and the other showed no benefit [102]. Therefore, while stimulants may be used for formally-diagnosed hypersomnia disorders in dementia patients, there is no evidence currently to recommend stimulants for general use in dementia. 


\section{Conclusion}

Sleep and circadian disturbances are common in all types of dementia, and can manifest in symptoms around-the-clock. The clinical approach to sleep and circadian disorders in dementia begins with assessing for and treating primary sleep disorders, then managing comorbid conditions and medications that may be negatively affecting sleep, then behavioral interventions, and then pharmacological treatments. Studies have shown neutral to positive effects of sleep hygiene education, physical and social activity, bright light therapy, and melatonin supplementation, without significant adverse side effects. There are scant data to support the use of hypnotic medications for sleep disturbances in dementia, with only one small study showing a benefit of low-dose trazodone. Due to risk of sedation, falls, and worse cognitive function from hypnotic medications, they should be used very cautiously, with frequent serial assessments for safety and objective measurements of drug efficacy. Well-designed studies using specific criteria for dementia etiology, formal assessment for primary sleep disorders, incorporation of circadian phenotype into treatment strategy, and treatment dosing and methods appropriate for the dementia population are sorely needed to identify truly effective interventions for sleep and circadian disturbances in dementia.

\section{References}

1. Ohayon MM, Carskadon MA, Guilleminault C, Vitiello MV. Meta-analysis of quantitative sleep parameters from childhood to old age in healthy individuals: developing normative sleep values across the human lifespan. Sleep. 2004; 27(7):1255-73. [PubMed: 15586779]

2. Tractenberg RE, Singer CM, Kaye JA. Symptoms of sleep disturbance in persons with Alzheimer's disease and normal elderly. Journal of sleep research. 2005; 14(2):177-85. [PubMed: 15910515]

3. Deschenes CL, McCurry SM. Current treatments for sleep disturbances in individuals with dementia. Current psychiatry reports. 2009; 11(1):20-6. [PubMed: 19187704]

4. Swaab DF, Fliers E, Partiman TS. The suprachiasmatic nucleus of the human brain in relation to sex, age and senile dementia. Brain Res. 1985; 342(1):37-44. [PubMed: 4041816]

5. Monk TH. Sleep and circadian rhythms. Exp Gerontol. 1991; 26(2-3):233-43. [PubMed: 1915693]

6. Bombois S, Derambure P, Pasquier F, Monaca C. Sleep disorders in aging and dementia. J Nutr Health Aging. 2010; 14(3):212-7. [PubMed: 20191256]

7. McCurry SM, Logsdon RG, Teri L, Gibbons LE, Kukull WA, Bowen JD, et al. Characteristics of sleep disturbance in community-dwelling Alzheimer's disease patients. J Geriatr Psychiatry Neurol. 1999; 12(2):53-9. [PubMed: 10483925]

8. Vitiello MV, Borson S. Sleep disturbances in patients with Alzheimer's disease: epidemiology, pathophysiology and treatment. CNS Drugs. 2001; 15(10):777-96. [PubMed: 11602004]

9. Ju YE, McLeland JS, Toedebusch CD, Xiong C, Fagan AM, Duntley SP, et al. Sleep quality and preclinical Alzheimer disease. JAMA Neurol. 2013; 70(5):587-93. [PubMed: 23479184]

10. Spira AP, Gamaldo AA, An Y, Wu MN, Simonsick EM, Bilgel M, et al. Self-reported sleep and beta-amyloid deposition in community-dwelling older adults. JAMA Neurol. 2013; 70(12):153743. [PubMed: 24145859]

11•. Ju YE, Lucey BP, Holtzman DM. Sleep and Alzheimer disease pathology--a bidirectional relationship. Nat Rev Neurol. 2014; 10(2):115-9. This article reviews animal and human data supporting the bi-directional link between sleep disturbance and accumulation of amyloid-beta plaques, a pathological hallmark of Alzheimer's Disease. [PubMed: 24366271]

12. Dauvilliers Y. Insomnia in patients with neurodegenerative conditions. Sleep medicine. 2007; 8(4):S27-34. [PubMed: 18346674]

13. Reynolds CF 3rd, Kupfer DJ, Taska LS, Hoch CC, Sewitch DE, Restifo K, et al. Sleep apnea in Alzheimer's dementia: correlation with mental deterioration. J Clin Psychiatry. 1985; 46(7):25761. [PubMed: 4008448] 
14. Ancoli-Israel S, Klauber MR, Butters N, Parker L, Kripke DF. Dementia in institutionalized elderly: relation to sleep apnea. J Am Geriatr Soc. 1991; 39(3):258-63. [PubMed: 2005339]

15. Guarnieri B, Adorni F, Musicco M, Appollonio I, Bonanni E, Caffarra P, et al. Prevalence of sleep disturbances in mild cognitive impairment and dementing disorders: a multicenter Italian clinical cross-sectional study on 431 patients. Dement Geriatr Cogn Disord. 2012; 33(1):50-8. [PubMed: 22415141]

16. Boddy F, Rowan EN, Lett D, O'Brien JT, McKeith IG, Burn DJ. Subjectively reported sleep quality and excessive daytime somnolence in Parkinson's disease with and without dementia, dementia with Lewy bodies and Alzheimer's disease. International journal of geriatric psychiatry. 2007; 22(6):529-35. [PubMed: 17096456]

17. Ondo WG, Dat Vuong K, Khan H, Atassi F, Kwak C, Jankovic J. Daytime sleepiness and other sleep disorders in Parkinson's disease. Neurology. 2001; 57(8):1392-6. [PubMed: 11673578]

18. Breen DP, Williams-Gray CH, Mason SL, Foltynie T, Barker RA. Excessive daytime sleepiness and its risk factors in incident Parkinson's disease. Journal of neurology, neurosurgery, and psychiatry. 2013; 84(2):233-4.

19. Fronczek R, Overeem S, Lee SY, Hegeman IM, van Pelt J, van Duinen SG, et al. Hypocretin (orexin) loss and sleep disturbances in Parkinson's Disease. Brain. 2008; 131(Pt 1):e88. [PubMed: 17898003]

20. Howell MJ, Schenck CH. Rapid Eye Movement Sleep Behavior Disorder and Neurodegenerative Disease. JAMA Neurol. 2015; 72(6):707-12. [PubMed: 25867792]

21. Rijsman RM, Schoolderman LF, Rundervoort RS, Louter M. Restless legs syndrome in Parkinson's disease. Parkinsonism Relat Disord. 2014; 20(1):S5-9. [PubMed: 24262188]

22. Leung RS, Comondore VR, Ryan CM, Stevens D. Mechanisms of sleep-disordered breathing: causes and consequences. Pflugers Archiv: European journal of physiology. 2012; 463(1):213-30. [PubMed: 22083643]

23. Harper DG, Stopa EG, McKee AC, Satlin A, Harlan PC, Goldstein R, et al. Differential circadian rhythm disturbances in men with Alzheimer disease and frontotemporal degeneration. Arch Gen Psychiatry. 2001; 58(4):353-60. [PubMed: 11296096]

24. Anderson KN, Hatfield C, Kipps C, Hastings M, Hodges JR. Disrupted sleep and circadian patterns in frontotemporal dementia. European journal of neurology. 2009; 16(3):317-23. [PubMed: 19170747]

25. Ancoli-Israel S, Ayalon L. Diagnosis and treatment of sleep disorders in older adults. The American journal of geriatric psychiatry: official journal of the American Association for Geriatric Psychiatry. 2006; 14(2):95-103. [PubMed: 16473973]

26. Johns MW. A new method for measuring daytime sleepiness: the Epworth sleepiness scale. Sleep. 1991; 14(6):540-5. [PubMed: 1798888]

27. Buysse DJ, Reynolds CF 3rd, Monk TH, Berman SR, Kupfer DJ. The Pittsburgh Sleep Quality Index: a new instrument for psychiatric practice and research. Psychiatry research. 1989; 28(2): 193-213. [PubMed: 2748771]

28. Tractenberg RE, Singer CM, Cummings JL, Thal LJ. The Sleep Disorders Inventory: an instrument for studies of sleep disturbance in persons with Alzheimer's disease. Journal of sleep research. 2003; 12(4):331-7. [PubMed: 14633245]

29. Hogl B, Arnulf I, Comella C, Ferreira J, Iranzo A, Tilley B, et al. Scales to assess sleep impairment in Parkinson's disease: critique and recommendations. Mov Disord. 2010; 25(16):2704-16. [PubMed: 20931631]

30. Morgenthaler T, Alessi C, Friedman L, Owens J, Kapur V, Boehlecke B, et al. Practice parameters for the use of actigraphy in the assessment of sleep and sleep disorders: an update for 2007. Sleep. 2007; 30(4):519-29. [PubMed: 17520797]

31. Masa JF, Corral J, Pereira R, Duran-Cantolla J, Cabello M, Hernandez-Blasco L, et al. Therapeutic decision-making for sleep apnea and hypopnea syndrome using home respiratory polygraphy: a large multicentric study. American journal of respiratory and critical care medicine. $2011 ; 184(8)$ : 964-71. [PubMed: 21737584] 
32. Yaffe K, Laffan AM, Harrison SL, Redline S, Spira AP, Ensrud KE, et al. Sleep-disordered breathing, hypoxia, and risk of mild cognitive impairment and dementia in older women. JAMA. 2011; 306(6):613-9. [PubMed: 21828324]

33•. Osorio RS, Gumb T, Pirraglia E, Varga AW, Lu SE, Lim J, et al. Sleep-disordered breathing advances cognitive decline in the elderly. Neurology. 2015; 84(19):1964-71. This is the largest study demonstrating an association between obstructive sleep apnea and incident Alzheimer's Disease. [PubMed: 25878183]

34. Ancoli-Israel S, Palmer BW, Cooke JR, Corey-Bloom J, Fiorentino L, Natarajan L, et al. Cognitive effects of treating obstructive sleep apnea in Alzheimer's disease: a randomized controlled study. $\mathbf{J}$ Am Geriatr Soc. 2008; 56(11):2076-81. [PubMed: 18795985]

35. Cooke JR, Ayalon L, Palmer BW, Loredo JS, Corey-Bloom J, Natarajan L, et al. Sustained use of CPAP slows deterioration of cognition, sleep, and mood in patients with Alzheimer's disease and obstructive sleep apnea: a preliminary study. J Clin Sleep Med. 2009; 5(4):305-9. [PubMed: 19968005]

36•. Troussiere AC, Charley CM, Salleron J, Richard F, Delbeuck X, Derambure P, et al. Treatment of sleep apnoea syndrome decreases cognitive decline in patients with Alzheimer's disease. J Neurol Neurosurg Psychiatry. 2014; 85(12):1405-8. This study provides a compelling reason to treat severe obstructive sleep apnea in Alzheimer's Disease patients. [PubMed: 24828897]

37. American Academy of Sleep Medicine. The International Classification of Sleep Disorders, Third Edition (ICSD-3). Darien, IL: American Academy of Sleep Medicine; 2014.

38. Aurora RN, Zak RS, Maganti RK, Auerbach SH, Casey KR, Chowdhuri S, et al. Best practice guide for the treatment of REM sleep behavior disorder (RBD). Journal of clinical sleep medicine: JCSM: official publication of the American Academy of Sleep Medicine. 2010; 6(1):85-95. [PubMed: 20191945]

39. Fereshtehnejad SM, Romenets SR, Anang JB, Latreille V, Gagnon JF, Postuma RB. New Clinical Subtypes of Parkinson Disease and Their Longitudinal Progression: A Prospective Cohort Comparison With Other Phenotypes. JAMA Neurol. 2015; 72(8):863-73. [PubMed: 26076039]

40. Hoch CC, Reynolds CF 3rd, Buysse DJ, Monk TH, Nowell P, Begley AE, et al. Protecting sleep quality in later life: a pilot study of bed restriction and sleep hygiene. J Gerontol B Psychol Sci Soc Sci. 2001; 56(1):P52-9. [PubMed: 11192338]

41. Alessi CA, Martin JL, Webber AP, Cynthia Kim E, Harker JO, Josephson KR. Randomized, controlled trial of a nonpharmacological intervention to improve abnormal sleep/wake patterns in nursing home residents. Journal of the American Geriatrics Society. 2005; 53(5):803-10. [PubMed: 15877555]

42. McCurry SM, Gibbons LE, Logsdon RG, Vitiello MV, Teri L. Nighttime insomnia treatment and education for Alzheimer's disease: a randomized, controlled trial. Journal of the American Geriatrics Society. 2005; 53(5):793-802. [PubMed: 15877554]

43. McCurry SM, LaFazia DM, Pike KC, Logsdon RG, Teri L. Development and evaluation of a sleep education program for older adults with dementia living in adult family homes. The American journal of geriatric psychiatry : official journal of the American Association for Geriatric Psychiatry. 2012; 20(6):494-504. [PubMed: 22367233]

44. Ouslander JG, Connell BR, Bliwise DL, Endeshaw Y, Griffiths P, Schnelle JF. A nonpharmacological intervention to improve sleep in nursing home patients: results of a controlled clinical trial. Journal of the American Geriatrics Society. 2006; 54(1):38-47. [PubMed: 16420196]

45. Naylor E, Penev PD, Orbeta L, Janssen I, Ortiz R, Colecchia EF, et al. Daily social and physical activity increases slow-wave sleep and daytime neuropsychological performance in the elderly. Sleep. 2000; 23(1):87-95. [PubMed: 10678469]

46. Benloucif S, Orbeta L, Ortiz R, Janssen I, Finkel SI, Bleiberg J, et al. Morning or evening activity improves neuropsychological performance and subjective sleep quality in older adults. Sleep. 2004; 27(8):1542-51. [PubMed: 15683146]

47. Richards KC, Lambert C, Beck CK, Bliwise DL, Evans WJ, Kalra GK, et al. Strength training, walking, and social activity improve sleep in nursing home and assisted living residents: randomized controlled trial. Journal of the American Geriatrics Society. 2011; 59(2):214-23. [PubMed: 21314643] 
48. Richards KC, Beck C, O'Sullivan PS, Shue VM. Effect of individualized social activity on sleep in nursing home residents with dementia. Journal of the American Geriatrics Society. 2005; 53(9): 1510-7. [PubMed: 16137280]

49. Eggermont LH, Blankevoort CG, Scherder EJ. Walking and night-time restlessness in mild-tomoderate dementia: a randomized controlled trial. Age Ageing. 2010; 39(6):746-9. [PubMed: 20823127]

50. McCurry SM, Pike KC, Vitiello MV, Logsdon RG, Larson EB, Teri L. Increasing walking and bright light exposure to improve sleep in community-dwelling persons with Alzheimer's disease: results of a randomized, controlled trial. Journal of the American Geriatrics Society. 2011; 59(8): 1393-402. [PubMed: 21797835]

51. Nascimento CM, Ayan C, Cancela JM, Gobbi LT, Gobbi S, Stella F. Effect of a multimodal exercise program on sleep disturbances and instrumental activities of daily living performance on Parkinson's and Alzheimer's disease patients. Geriatr Gerontol Int. 2014; 14(2):259-66. [PubMed: 23647635]

52. Tewary S, C N, Pandya N, McCurry SM. Pilot test of a six-week group delivery caregiver training program to reduce sleep disturbances among older adults with dementia-Innovative Practice. Dementia (London). 2016 Apr 4. Epub ahead of print.

53. Morgenthaler TI, Lee-Chiong T, Alessi C, Friedman L, Aurora RN, Boehlecke B, et al. Practice parameters for the clinical evaluation and treatment of circadian rhythm sleep disorders. An American Academy of Sleep Medicine report. Sleep. 2007; 30(11):1445-59. [PubMed: 18041479]

54•. Forbes D, Blake CM, Thiessen EJ, Peacock S, Hawranik P. Light therapy for improving cognition, activities of daily living, sleep, challenging behaviour, and psychiatric disturbances in dementia. Cochrane Database Syst Rev. 2014; (2):CD003946. This recent Cochrane meta-analysis reviews the effect of bright light therapy, not only on sleep but other symptoms of dementia. [PubMed: 24574061]

55. Ancoli-Israel S, Gehrman P, Martin JL, Shochat T, Marler M, Corey-Bloom J, et al. Increased light exposure consolidates sleep and strengthens circadian rhythms in severe Alzheimer's disease patients. Behavioral sleep medicine. 2003; 1(1):22-36. [PubMed: 15600135]

56. Dowling GA, Mastick J, Hubbard EM, Luxenberg JS, Burr RL. Effect of timed bright light treatment for rest-activity disruption in institutionalized patients with Alzheimer's disease. International journal of geriatric psychiatry. 2005; 20(8):738-43. [PubMed: 16035127]

57. Burns A, Allen H, Tomenson B, Duignan D, Byrne J. Bright light therapy for agitation in dementia: a randomized controlled trial. International psychogeriatrics / IPA. 2009; 21(4):711-21.

58. Dowling GA, Burr RL, Van Someren EJ, Hubbard EM, Luxenberg JS, Mastick J, et al. Melatonin and bright-light treatment for rest-activity disruption in institutionalized patients with Alzheimer's disease. J Am Geriatr Soc. 2008; 56(2):239-46. [PubMed: 18070004]

59. Lyketsos CG, Lindell Veiel L, Baker A, Steele C. A randomized, controlled trial of bright light therapy for agitated behaviors in dementia patients residing in long-term care. International journal of geriatric psychiatry. 1999; 14(7):520-5. [PubMed: 10440971]

60. Mishima K, Hishikawa Y, Okawa M. Randomized, dim light controlled, crossover test of morning bright light therapy for rest-activity rhythm disorders in patients with vascular dementia and dementia of Alzheimer's type. Chronobiology international. 1998; 15(6):647-54. [PubMed: 9844752]

61. Riemersma-van der Lek RF, Swaab DF, Twisk J, Hol EM, Hoogendijk WJ, Van Someren EJ. Effect of bright light and melatonin on cognitive and noncognitive function in elderly residents of group care facilities: a randomized controlled trial. JAMA. 2008; 299(22):2642-55. [PubMed: 18544724]

62. Fontana Gasio P, Krauchi K, Cajochen C, Someren E, Amrhein I, Pache M, et al. Dawn-dusk simulation light therapy of disturbed circadian rest-activity cycles in demented elderly. Experimental gerontology. 2003; 38(1-2):207-16. [PubMed: 12543279]

63. Nowak L. The effect of timed blue-green light on sleep-wake patterns in women with Alzheimer's disease. Dissertation Abstracts International: Section B: The Sciences and Engineering. 2008; 69(6-B):1-154. 
64. Sloane PD, Figueiro M, Garg S, Cohen LW, Reed D, Williams CS, et al. Effect of home-based light treatment on persons with dementia and their caregivers. Light Res Technol. 2015; 47(2):161-76. [PubMed: 26273229]

65. Figueiro MG, Plitnick BA, Lok A, Jones GE, Higgins P, Hornick TR, et al. Tailored lighting intervention improves measures of sleep, depression, and agitation in persons with Alzheimer's disease and related dementia living in long-term care facilities. Clinical interventions in aging. 2014; 9:1527-37. [PubMed: 25246779]

66• van Maanen A, Meijer AM, van der Heijden KB, Oort FJ. The effects of light therapy on sleep problems: A systematic review and meta-analysis. Sleep medicine reviews. 2015; 29:52-62. This meta-analysis examines the effect of bright light therapy specifically on sleep. [PubMed: 26606319]

67. Fetveit A, Skjerve A, Bjorvatn B. Bright light treatment improves sleep in institutionalised elderly--an open trial. International journal of geriatric psychiatry. 2003; 18(6):520-6. [PubMed: 12789673]

68. Colenda CC, Cohen W, McCall WV, Rosenquist PB. Phototherapy for patients with Alzheimer disease with disturbed sleep patterns: results of a community-based pilot study. Alzheimer disease and associated disorders. 1997; 11(3):175-8.

69. Kobayashi R, Fukuda N, Kohsaka M, Sasamoto Y, Sakakibara S, Koyama E, et al. Effects of bright light at lunchtime on sleep of patients in a geriatric hospital I. Psychiatry and clinical neurosciences. 2001; 55(3):287-9. [PubMed: 11422879]

70. Satlin A, Volicer L, Ross V, Herz L, Campbell S. Bright light treatment of behavioral and sleep disturbances in patients with Alzheimer's disease. The American journal of psychiatry. 1992; 149(8):1028-32. [PubMed: 1353313]

71. Skjerve A, Holsten F, Aarsland D, Bjorvatn B, Nygaard HA, Johansen IM. Improvement in behavioral symptoms and advance of activity acrophase after short-term bright light treatment in severe dementia. Psychiatry and clinical neurosciences. 2004; 58(4):343-7. [PubMed: 15298644]

72. Kwok T, Leung PC, Wing YK, Ip I, Wong B, Ho DW, et al. The effectiveness of acupuncture on the sleep quality of elderly with dementia: a within-subjects trial. Clinical interventions in aging. 2013; 8:923-9. [PubMed: 23940415]

73. Simoncini M, Gatti A, Quirico PE, Balla S, Capellero B, Obialero R, et al. Acupressure in insomnia and other sleep disorders in elderly institutionalized patients suffering from Alzheimer's disease. Aging clinical and experimental research. 2015; 27(1):37-42. [PubMed: 24878886]

74. Harris M, Richards KC, Grando VT. The effects of slow-stroke back massage on minutes of nighttime sleep in persons with dementia and sleep disturbances in the nursing home: a pilot study. J Holist Nurs. 2012; 30(4):255-63. [PubMed: 23007716]

75. Wang W, Sawada M, Noriyama Y, Arita K, Ota T, Sadamatsu M, et al. Tai Chi exercise versus rehabilitation for the elderly with cerebral vascular disorder: a single-blinded randomized controlled trial. Psychogeriatrics. 2010; 10(3):160-6. [PubMed: 20860572]

76. Tanaka M, Ishii A, Yamano E, Ogikubo H, Okazaki M, Kamimura K, et al. Effect of a human-type communication robot on cognitive function in elderly women living alone. Med Sci Monit. 2012; 18(9):CR550-7. [PubMed: 22936190]

77. Skene DJ, Vivien-Roels B, Sparks DL, Hunsaker JC, Pevet P, Ravid D, et al. Daily variation in the concentration of melatonin and 5-methoxytryptophol in the human pineal gland: effect of age and Alzheimer's disease. Brain Res. 1990; 528(1):170-4. [PubMed: 2245336]

78. Uchida K, Okamoto N, Ohara K, Morita Y. Daily rhythm of serum melatonin in patients with dementia of the degenerate type. Brain Res. 1996; 717(1-2):154-9. [PubMed: 8738265]

79. Cardinali DP, Vigo DE, Olivar N, Vidal MF, Furio AM, Brusco LI. Therapeutic application of melatonin in mild cognitive impairment. American journal of neurodegenerative disease. 2012; 1(3):280-91. [PubMed: 23383398]

80. Serfaty M, Kennell-Webb S, Warner J, Blizard R, Raven P. Double blind randomised placebo controlled trial of low dose melatonin for sleep disorders in dementia. Int J Geriatr Psychiatry. 2002; 17(12):1120-7. [PubMed: 12461760] 
81. Singer C, Tractenberg RE, Kaye J, Schafer K, Gamst A, Grundman M, et al. A multicenter, placebo-controlled trial of melatonin for sleep disturbance in Alzheimer's disease. Sleep. 2003; 26(7):893-901. [PubMed: 14655926]

82•. McCleery J, Cohen DA, Sharpley AL. Pharmacotherapies for sleep disturbances in Alzheimer's disease. Cochrane Database Syst Rev. 2014; (3):CD009178. This comprehensive Cochrane metaanalysis reviews pharmacological therapies, including melatonin, for sleep disturbances.

[PubMed: 24659320]

83. Xu J, Wang LL, Dammer EB, Li CB, Xu G, Chen SD, et al. Melatonin for sleep disorders and cognition in dementia: a meta-analysis of randomized controlled trials. American journal of Alzheimer's disease and other dementias. 2015; 30(5):439-47.

84. Asayama K, Yamadera H, Ito T, Suzuki H, Kudo Y, Endo S. Double blind study of melatonin effects on the sleep-wake rhythm, cognitive and non-cognitive functions in Alzheimer type dementia. J Nippon Med Sch. 2003; 70(4):334-41. [PubMed: 12928714]

85. Gehrman PR, Connor DJ, Martin JL, Shochat T, Corey-Bloom J, Ancoli-Israel S. Melatonin fails to improve sleep or agitation in double-blind randomized placebo-controlled trial of institutionalized patients with Alzheimer disease. Am J Geriatr Psychiatry. 2009; 17(2):166-9. [PubMed: 19155748]

86. Gao QW, LY G, Xiang W, Peng KR. Effect of melatonin on mild Alzheimer's disease in elderly male patients. Parct Geriatr. 2009; 23(1):56-8.

87. Wade AG, Farmer M, Harari G, Fund N, Laudon M, Nir T, et al. Add-on prolonged-release melatonin for cognitive function and sleep in mild to moderate Alzheimer's disease: a 6-month, randomized, placebo-controlled, multicenter trial. Clin Interv Aging. 2014; 9:947-61. [PubMed: 24971004]

88. [Accessed June 18, 2016] Clinical Trial Synopsis 01-05-TL-375-061, NCT\# 00325728: A doubleblind, randomized, placebo- controlled study of the efficacy, safety and tolerability of 8 week treatment of Rozerem $8 \mathrm{mg}$ (QHS) in sleep disturbed, mild to moderately severe Alzheimer's disease subjects. http://www.takeda.com/research/ct/pdf/report/15_Ramelteon_01-05TL-375-061_ClinicalTrialSynopsis_NCT00325728_en.pdf

89. Kasanuki K, Iseki E, Nishida Y, Fujishiro H, Chiba Y, Sato K, et al. Effectiveness of ramelteon for treatment of visual hallucinations in dementia with Lewy bodies: a report of 4 cases. Journal of clinical psychopharmacology. 2013; 33(4):581-3. [PubMed: 23771196]

90• Camargos EF, Louzada LL, Quintas JL, Naves JO, Louzada FM, Nobrega OT. Trazodone improves sleep parameters in Alzheimer disease patients: a randomized, double-blind, and placebo-controlled study. The American journal of geriatric psychiatry : official journal of the American Association for Geriatric Psychiatry. 2014; 22(12):1565-74. To date, this study is the only randomized, controlled study of a non-melatonin medication showing a benefit on sleep in dementia. [PubMed: 24495406]

91. Scoralick FM, Louzada LL, Quintas JL, Naves JO, Camargos EF, Nobrega OT. Mirtazapine does not improve sleep disorders in Alzheimer's disease: results from a double-blind, placebo-controlled pilot study. Psychogeriatrics : the official journal of the Japanese Psychogeriatric Society. 2016

92. Romeo R, Knapp M, Hellier J, Dewey M, Ballard C, Baldwin R, et al. Cost-effectiveness analyses for mirtazapine and sertraline in dementia: randomised controlled trial. Br J Psychiatry. 2013; 202:121-8. [PubMed: 23258767]

93. Vermeeren A, Coenen AM. Effects of the use of hypnotics on cognition. Progress in brain research. 2011; 190:89-103. [PubMed: 21531246]

94. Billioti de Gage S, Moride Y, Ducruet T, Kurth T, Verdoux H, Tournier M, et al. Benzodiazepine use and risk of Alzheimer's disease: case-control study. Bmj. 2014; 349:g5205. [PubMed: 25208536]

95. Defrancesco M, Marksteiner J, Fleischhacker WW, Blasko I. Use of Benzodiazepines in Alzheimer's Disease: A Systematic Review of Literature. The international journal of neuropsychopharmacology / official scientific journal of the Collegium Internationale Neuropsychopharmacologicum. 2015; 18(10):pyv055.

96. Rosenberg PB. Benzodiazepine exposure increases risk of Alzheimer's disease. Evidence-based medicine. 2015; 20(2):75. [PubMed: 25666019] 
97. Zhang Y, Zhou XH, Meranus DH, Wang L, Kukull WA. Benzodiazepine Use and Cognitive Decline in Elderly With Normal Cognition. Alzheimer disease and associated disorders. 2016; 30(2):113-7. [PubMed: 26067923]

98. Closser MH. Benzodiazepines and the elderly. A review of potential problems. Journal of substance abuse treatment. 1991; 8(1-2):35-41. [PubMed: 1675691]

99. Larsson V, Aarsland D, Ballard C, Minthon L, Londos E. The effect of memantine on sleep behaviour in dementia with Lewy bodies and Parkinson's disease dementia. Int J Geriatr Psychiatry. 2010; 25(10):1030-8. [PubMed: 20872929]

100. Yin Y, Liu Y, Zhuang J, Pan X, Li P, Yang Y, et al. Low-Dose Atypical Antipsychotic Risperidone Improves the 5-Year Outcome in Alzheimer's Disease Patients with Sleep Disturbances. Pharmacology. 2015; 96(3-4):155-62. [PubMed: 26279176]

101. Lou JS, Dimitrova DM, Park BS, Johnson SC, Eaton R, Arnold G, et al. Using modafinil to treat fatigue in Parkinson disease: a double-blind, placebo-controlled pilot study. Clin Neuropharmacol. 2009; 32(6):305-10. [PubMed: 19620846]

102. Ondo WG, Fayle R, Atassi F, Jankovic J. Modafinil for daytime somnolence in Parkinson's disease: double blind, placebo controlled parallel trial. J Neurol Neurosurg Psychiatry. 2005; 76(12):1636-9. [PubMed: 16291885] 


\section{Opinion statement}

Sleep and circadian disorders occur frequently in all types of dementia. Due to the multifactorial nature of sleep problems in dementia, we propose a structured approach to the evaluation and treatment of these patients. Primary sleep disorders such as obstructive sleep apnea should be treated first. Comorbid conditions and medications that impact sleep should be optimally managed to minimize negative effects on sleep. Patients and caregivers should maintain good sleep hygiene, and social and physical activity should be encouraged during the daytime. Given the generally benign nature of bright light therapy and melatonin, these treatments should be tried first. Pharmacological treatments should be added cautiously, due to the risk of cognitive side effects, sedation, and falls in the demented and older population. Regardless of treatment modality, it is essential to follow patients with dementia and sleep disorders closely, with serial monitoring of individual response to treatment. 
Table 1

\section{Recommended clinical approach to sleep disorders in dementia}

Current existing evidence and expert guidelines on the evaluation and treatment of sleep disorders in dementia are summarized. The approach should proceed in the listed order, starting with "Clinical Assessments," and proceeding downward only if symptoms persist. "Benefits" listed for sleep treatments include only RCT's and meta-analyses.

\begin{tabular}{|c|c|c|c|c|}
\hline Assessment or Treatment & Details & Benefits & Cons & Notes \\
\hline \multicolumn{5}{|l|}{ Clinical Assessments } \\
\hline History & $\begin{array}{l}\text { Collateral source is critical } \\
\text { Collect information about symptoms of } \\
\text { primary sleep disorders, sleep habits/ } \\
\text { hygiene, co-morbidities, medications, } \\
\text { dementia-specific symptoms } \\
\text { Assess for depression and anxiety }\end{array}$ & & Time-intensive & $\begin{array}{l}\text { Obtain } \\
\text { information } \\
\text { about caregiver } \\
\text { burden }\end{array}$ \\
\hline $\begin{array}{l}\text { Sleep scales and } \\
\text { questionnaires }\end{array}$ & $\begin{array}{l}\text { General: Epworth Sleepiness Scale, } \\
\text { Pittsburgh Sleep Quality Index, Insomnia } \\
\text { severity index, etc } \\
\text { Dementia-specific: Sleep Disturbance } \\
\text { Inventory, SCOPA sleep scale, etc }\end{array}$ & & & $\begin{array}{l}\text { Use serially to } \\
\text { determine } \\
\text { response to } \\
\text { treatment }\end{array}$ \\
\hline Actigraphy & $\begin{array}{l}\text { Several days to weeks } \\
\text { To assess circadian phase and amplitude } \\
\text { To assess nocturnal sleep variables }\end{array}$ & $\begin{array}{l}\text { Non-invasive, able to } \\
\text { get data in patient's } \\
\text { usual setting }\end{array}$ & $\begin{array}{l}\text { Usually not reimbursed } \\
\text { by insurers }\end{array}$ & $\begin{array}{l}\text { Obtain } \\
\text { concurrent } \\
\text { sleep log } \\
\text { Use serially to } \\
\text { determine } \\
\text { response to } \\
\text { treatment }\end{array}$ \\
\hline Polysomnogram & $\begin{array}{l}\text { For suspected obstructive sleep apnea, } \\
\text { periodic limb movement disorder, RBD (or } \\
\text { other parasomnia) }\end{array}$ & Gold standard diagnosis & $\begin{array}{l}\text { Inconvenient } \\
\text { Demented patients may } \\
\text { have confusion/agitation }\end{array}$ & $\begin{array}{l}\text { Caregiver } \\
\text { should stay } \\
\text { with patient if } \\
\text { possible } \\
\text { Ambulatory } \\
\text { (home) studies } \\
\text { may have high } \\
\text { failure rate in } \\
\text { dementia }\end{array}$ \\
\hline \multicolumn{5}{|c|}{ Treat primary sleep disorder } \\
\hline Obstructive sleep apnea & Positive airway pressure & $\begin{array}{l}\text { Slower cognitive } \\
\text { decline } \\
\text { Less snoring, improved } \\
\text { sleep, improved } \\
\text { daytime alertness }\end{array}$ & $\begin{array}{l}\text { Patients may not be able } \\
\text { to tolerate PAP Caregiver } \\
\text { burden }\end{array}$ & $\begin{array}{l}\text { Common in } \\
\text { AD, vascular } \\
\text { dementia } \\
\text { No data on } \\
\text { non-PAP } \\
\text { treatments }\end{array}$ \\
\hline Restless legs syndrome & $\begin{array}{l}\text { Iron supplementation } \\
\text { Dopamine agonists, gabapentin, other } \\
\text { typical RLS medications }\end{array}$ & Improve symptoms & $\begin{array}{l}\text { Sleep attacks and } \\
\text { compulsive/addictive } \\
\text { behavior with dopamine } \\
\text { agonists } \\
\text { Sedation with gabapentin }\end{array}$ & $\begin{array}{l}\text { Common in PD } \\
\text { Coordinate } \\
\text { dopamine } \\
\text { agonists with } \\
\text { PD doctor }\end{array}$ \\
\hline $\begin{array}{l}\text { REM sleep behavior } \\
\text { disorder }\end{array}$ & $\begin{array}{l}\text { Clonazepam or melatonin } \\
\text { Safety precautions }\end{array}$ & Reduced risk of injury & Sedation with clonazepam & $\begin{array}{l}\text { In DLB and } \\
\text { PDD }\end{array}$ \\
\hline Hypersomnia & $\begin{array}{l}\text { Stimulants, sodium oxybate, anti-cataplectic } \\
\text { agents }\end{array}$ & Improve alertness & $\begin{array}{l}\text { Cardiovascular risk, } \\
\text { irritability, risk of abuse/ } \\
\text { dependence } \\
\text { Sedation with sodium } \\
\text { oxybate }\end{array}$ & $\begin{array}{l}\text { Common in } \\
\text { DLB and PDD } \\
\text { Only for true } \\
\text { primary } \\
\text { hypersomnia } \\
\text { such as } \\
\text { narcolepsy }\end{array}$ \\
\hline
\end{tabular}

Curr Treat Options Neurol. Author manuscript; available in PMC 2017 September 01. 


\begin{tabular}{|c|c|c|c|c|}
\hline Assessment or Treatment & Details & Benefits & Cons & Notes \\
\hline $\begin{array}{l}\text { Treat mood and anxiety } \\
\text { disorders }\end{array}$ & Anti-depressants, psychotherapy, anxiolytics & $\begin{array}{l}\text { Improve psychiatric } \\
\text { and sleep symptoms } \\
\text { (usually insomnia) }\end{array}$ & $\begin{array}{l}\text { May cause sedation and } \\
\text { worse cognition Worse } \\
\text { RLS } \\
\text { Time-intensive }\end{array}$ & $\begin{array}{l}\text { Coordinate } \\
\text { with other } \\
\text { physicians and } \\
\text { healthcare } \\
\text { professionals }\end{array}$ \\
\hline $\begin{array}{l}\text { Treat pain, and other co- } \\
\text { morbidites causing } \\
\text { disrupted sleep }\end{array}$ & Varies & Improve sleep & $\begin{array}{l}\text { Pain and bladder } \\
\text { medications may cause } \\
\text { sedation and worse } \\
\text { cognition } \\
\text { Varies by co-morbidity } \\
\text { Time-intensive }\end{array}$ & $\begin{array}{l}\text { Coordinate } \\
\text { with other } \\
\text { physicians and } \\
\text { healthcare } \\
\text { professionals }\end{array}$ \\
\hline $\begin{array}{l}\text { Minimize or adjust } \\
\text { medications causing sleep } \\
\text { disruption or hypersomnia }\end{array}$ & $\begin{array}{l}\text { Dementia and Parkinsomnism medications } \\
\text { Pain medications, stimulants, } \beta 2 \text { agonist } \\
\text { inhalers, anti-hypertensives, bladder } \\
\text { medications, anti-retrovirals, steroids, etc }\end{array}$ & Improve sleep & $\begin{array}{l}\text { Varies by medication } \\
\text { Time-intensive }\end{array}$ & $\begin{array}{l}\text { Coordinate } \\
\text { with other } \\
\text { physicians and } \\
\text { healthcare } \\
\text { professionals }\end{array}$ \\
\hline \multicolumn{5}{|l|}{ Behavioral sleep treatments } \\
\hline Sleep hygiene education & See text Frequently used in MMT & $\begin{array}{l}\text { Modest improvement in } \\
\text { TST in one study (43) }\end{array}$ & $\begin{array}{l}\text { Caregiver and patient } \\
\text { burden }\end{array}$ & $\begin{array}{l}\text { May be } \\
\text { difficult to } \\
\text { implement in } \\
\text { institutionalized } \\
\text { setting }\end{array}$ \\
\hline Physical activity & $\begin{array}{l}\text { 3-5 times per week, } 30-60 \text { minutes, } \\
\text { vigorous } \\
\text { Can use in MMT }\end{array}$ & $\begin{array}{l}\text { Neutral effect on } \\
\text { actigraphy measures } \\
(42,49,50) \\
\text { Vigorous activity } \\
\text { showed modest } \\
\text { improvements in } \\
\text { subject sleep scales in } \\
\text { one study (51) }\end{array}$ & $\begin{array}{l}\text { Caregiver and patient } \\
\text { burden } \\
\text { Discomfort or } \\
\text { cardiovascular risk for } \\
\text { patients with co- } \\
\text { morbidities }\end{array}$ & $\begin{array}{l}\text { Ideally with } \\
\text { professional } \\
\text { therapist or } \\
\text { trainer }\end{array}$ \\
\hline Social activity & $\begin{array}{l}\text { Unknown } \\
\text { Better in MMT with physical activity }\end{array}$ & $\begin{array}{l}\text { One small study } \\
\text { showed improvement in } \\
\text { TST and reduced } \\
\text { daytime sleep (48) }\end{array}$ & $\begin{array}{l}\text { Caregiver and patient } \\
\text { burden }\end{array}$ & No standard \\
\hline Bright light therapy (BLT) & $\begin{array}{l}\text { Morning, 2500-10000 lux, 1-2 hours Can } \\
\text { use in MMT }\end{array}$ & $\begin{array}{l}\text { Reduced night-time } \\
\text { awakenings (meta- } \\
\text { analysis; 54) } \\
\text { Increased total sleep } \\
\text { time if patients have } \\
\text { pre-existing sleep } \\
\text { complaint (meta- } \\
\text { analysis; 66) }\end{array}$ & $\begin{array}{l}\text { Caregiver and patient } \\
\text { burden Eyestrain }\end{array}$ & $\begin{array}{l}\text { Ideally assess } \\
\text { circadian phase, } \\
\text { and time } \\
\text { therapy to shift } \\
\text { phase } \\
\text { appropriately }\end{array}$ \\
\hline $\begin{array}{l}\text { Complementary and } \\
\text { alternative modalities }\end{array}$ & Varies, see text & No large RCT & Varies & $\begin{array}{l}\text { If no adverse } \\
\text { effects and low } \\
\text { cost, reasonable } \\
\text { to try with } \\
\text { close } \\
\text { monitoring }\end{array}$ \\
\hline \multicolumn{5}{|c|}{ Pharmacological sleep treatments } \\
\hline Melatonin & $\begin{array}{l}\text { Studies support } 2-5 \mathrm{mg} \text { immediate release, } \\
\text { at bedtime. Recommended starting dose } \\
1.5 \mathrm{mg} \text {, increase by } 1-2 \mathrm{mg} \text { every few days; } \\
\text { additional benefit unlikely above } 10 \mathrm{mg} \text {. } \\
\text { Can use in MMT particularly with BLT }\end{array}$ & $\begin{array}{l}\sim 25 \text { minutes total sleep } \\
\text { time (meta-analysis; } \\
83 \text { ) }\end{array}$ & $\begin{array}{l}\text { One study showed } \\
\text { increased depressive } \\
\text { symptoms. } \\
\text { Sedating effect may be } \\
\text { more pronounced in } \\
\text { elderly or demented } \\
\text { patients, therefore assess } \\
\text { for risk of falls/injuries. }\end{array}$ & $\begin{array}{l}\text { No data on } \\
\text { dosing other } \\
\text { times of day }\end{array}$ \\
\hline Sedating anti-depressants & $\begin{array}{l}\text { Study supports Trazodone } 50 \mathrm{mg} \text {, at } \\
\text { bedtime. Recommend starting dose } 25 \mathrm{mg} \text {, } \\
\text { increase by } 25 \mathrm{mg} \text { increments. Max } 200 \mathrm{mg} \text {. } \\
\text { Taper gradually if }>50 \mathrm{mg} \text {. }\end{array}$ & $\begin{array}{l}42.5 \text { minutes total sleep } \\
\text { time in one study (90) }\end{array}$ & $\begin{array}{l}\text { May cause sedation and } \\
\text { increased risk of falls/ } \\
\text { injuries. particularly in } \\
\text { elderly/demented } \\
\text { Worse cognition,. in } \\
\text { dementia } \\
\text { Worse RLS }\end{array}$ & \\
\hline
\end{tabular}

Curr Treat Options Neurol. Author manuscript; available in PMC 2017 September 01. 


\begin{tabular}{|c|c|c|c|c|c|}
\hline \multirow{4}{*}{ 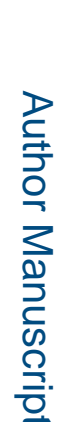 } & Assessment or Treatment & Details & Benefits & Cons & Notes \\
\hline & NBBRA & $\begin{array}{l}\text { No data to support specific treatment } \\
\text { Typical doses for elderly: zolpidem } 2.5-5 \\
\text { mg, eszopiclone } 0.5-2 \mathrm{mg} \text {, zaleplon } 5-10 \mathrm{mg} \text {. }\end{array}$ & No large RCT & $\begin{array}{l}\text { May cause sedation and } \\
\text { worse cognition Falls/ } \\
\text { injuries, especially in } \\
\text { elderly Parasomnias }\end{array}$ & \\
\hline & Benzodiazepines & No data to support specific treatment & No large RCT & $\begin{array}{l}\text { May cause sedation and } \\
\text { worse cognition Falls/ } \\
\text { injuries } \\
\text { Risk of abuse/dependence }\end{array}$ & \\
\hline & Stimulants & No data to support specific treatment & No large RCT & $\begin{array}{l}\text { Cardiovascular risk, } \\
\text { irritability, risk of abuse/ } \\
\text { dependence }\end{array}$ & \\
\hline
\end{tabular}

MMT $=$ Multi-modality treatment

$\mathrm{RCT}=$ Randomized controlled trial

RLS $=$ Restless legs syndrome

NBBRA = Non-benzodiazepine benzodiazepine receptor agonists

BLT $=$ Bright light therapy 